\title{
Presentación: Judith Butler: política y performatividad
}

\author{
Jesús GONZÁLEZ FisAC*
}

Universidad de Cádiz

NuRIA SÁNCHEZ MADRID**

Universidad Complutense de Madrid

En la obra de Judith Butler pueden señalarse dos elementos que han permanecido invariables a lo largo de su evolución. En primer lugar, su compromiso político, guiado no tanto por un proyecto y agenda concretos cuanto por una constante demanda homologable al "derecho a tener derechos" planteado por Hannah Arendt. En segundo lugar, su compromiso teórico con una lectura fenomenológica de la producción de realidades, incluidas las que protagonizan el campo político, según muestra su teoría de la performatividad.

Butler es bien conocida por su lucha en pro de la agencia política y el reconocimiento de gays y lesbianas, a los que se ha negado tradicionalmente la dignidad que merecen sus vidas y sus duelos, y cuyo activismo ha sido, por lo general, ninguneado. Desde finales de los años 80 sus propuestas políticas se encuentran estrechamente relacionadas con las demandas de estos colectivos. Huelga decir que también lo están con las causas del feminismo, el cual ha luchado asimismo desde la Ilustración por alcanzar un espacio de agencia y de reconocimiento para el colectivo de las mujeres. A estos precedentes debe añadirse que desde la primera década de este siglo sus trabajos se han ocupado de manera prioritaria de los derechos de los parias y sin papeles, de los refugiados y los represaliados, denunciando los mecanismos que opacan su presencia, empezando por la corporal. En esta misma línea, el objeto de sus últimos trabajos han sido acciones públicas colectivas como la ocupación de las plazas públicas Tahrir y Taksim o el Occupy Wall Street, al igual que su denuncia de la

\footnotetext{
*jesus.gonzalez@uca.es

ORCID iD: http://orcid.org/0000-0002-3967-506X

** nuriasma@filos.ucm.es

ORCID iD: http://orcid.org/0000-0003-4273-5948
} 
creciente precariedad humana a nivel global, tanto material como jurídica, tolerada por los regímenes legales existentes. En cualquier caso, todas estas líneas de trabajo están atravesadas por un mismo interés, a saber, la lucha por el reconocimiento y la visibilidad discursiva y política de quienes se ven expulsados del campo político (colectivo LGBT, mujeres, apátridas, indignados), con el consiguiente análisis de la economía de estas exclusiones.

Podría parecer que Butler ha desplazado su interés progresivamente del campo de la política de género al de la política sin más, incluso al de la política seria, al haberse concentrado en sus trabajos de las dos últimas décadas en las demandas derivadas de las condiciones materiales de la existencia. Pero este desplazamiento, denunciado hace tiempo por la autora como una forma de marginar los estudios de género bajo la rúbrica de lo "meramente cultural", ${ }^{1}$ no es tal. Butler ha sido consciente todo el tiempo de que no puede elaborarse una filosofía del género si la empresa no se acomete de modo rigurosamente político. Sin intervención política no hay producción de identidad. En su particular confrontación con Arendt, Butler recoge y reutiliza la expresión del básico "derecho a tener derechos" como una estructura radical de toda subjetivación. En esta expresión, podría decirse así, está inscrita la demanda de un campo político que no caiga en los errores de la exclusión. Para que haya derechos tiene que haber sujetos de derechos, de naturaleza múltiple, cuyas formas variables de constitución son la verdadera crux de toda teoría política. El campo político, como en general ocurre con cualquier campo de reconocimiento, no puede eludir sus consecuencias normativas. Una de las críticas más frecuentes a los planteamientos de Butler estriba en el hecho de que parece haber apuntado de manera prioritaria a la maleabilidad de la norma, sin proponer positivamente ningún sistema normativo concreto, como podría ser el caso del ejemplo suministrado por la Declaración Universal de los Derechos Humanos. En el campo del género se imponía la denuncia de la violencia de la norma y la consolidación de posibilidades de insurgencia. Pero el alcance de la lectura que Butler hace de la noción de campo, que se nutre de la fenomenología interna al lenguaje y al campo visual, atiende a las virtualidades de transformación interna de la norma, lo que pone de manifiesto una suerte de debilidad constitutiva en el seno de todo presunto sistema normativo. Concretamente, es en el origen de las normas donde se revela precisamente la contingencia del fundamento y con ello la posibilidad de su propia tendencia al cambio y resistencia a él. Por este motivo, Butler ha sido especialmente crítica con el modelo emancipatorio ilustrado, que parece esbozar la solución antes que agotar los pliegues del problema, toda vez que la emancipación supone en este contexto un sujeto anterior y no cuestio-

${ }^{1}$ Cf. J. Butler, "Merely Cultural”, New Left Review, 227 (1998), p. 33-44. 
nado. El hecho de que el campo de género sea un sistema de normas sedimentado en el tiempo, cuya consistencia confirma la ejecución afortunada y persistente de las mismas, lo expone a la transformación, pero también a una constante reelaboración y expansión. El sujeto-mujer no tiene por qué excluir a otros sujetos, como tampoco puede ser excluido de problematizaciones el sujeto queer o el indocumentado.

La potencialidad de una insurgencia intrínseca ha sido vislumbrada por Butler a propósito del cuerpo, de nuevo con ayuda de un peculiar enfoque fenomenológico. Toda vez que el cuerpo no puede reducirse a discurso, en su actuación se da siempre un lapsus necesario que permite la desviación. Para Butler el sujeto no es el sujeto epistémico y transparente -autofundado- de la tradición cartesiana. Tampoco coincide con su devenir como agente, esto es, con el sujeto volitivo y deliberativo de la tradición liberal. Esto tiene consecuencias de envergadura tanto para su epistemología como para su teoría de la acción. En efecto, Butler ha intentado apuntalar una subjetividad finita recurriendo a la teoría de los actos constitutivos de la fenomenología -partiendo sobre todo de Merleau-Ponty-, donde la acción se valora como un ejercicio corporal no completamente transparente. Pero también se acude asimismo a la teoría de los actos de habla de la "fenomenología lingüística" - planteada por Austin-, que ubica quiásticamente la emisión performativa en una totalidad inasequible. Lo mismo ocurre con el psicoanálisis -el de Freud, pero desde luego también el de Lacan-, cuya cartografía de la psique revela elecciones e identificaciones forcluidas, que se manifiestan esenciales para la recuperación de lo que somos. El rédito que arroja esta subjetividad reconstruida sobre el mismo campo normativo, incluyendo el político, no está cerrado ni se agota en sí mismo. Antes que un proyecto o una idea, se trata de una demanda constante de los cuerpos, de una sombra perpetua de lo corporal.

Esta cuestión nos conduce al segundo elemento que ha permanecido invariable en la trayectoria de Butler, que es la teoría de la performatividad. El hecho de que ciertas actuaciones resulten constitutivas y rindan efectos en el mundo como la identidad de género o como la identidad política-del individuo tanto como de la comunidad-, completa la ontología del sujeto y se compadece con la condición contingente del campo normativo. Butler se ha visto impelida a discutir insistentemente con quienes veían en la performatividad una nueva soberanía del sujeto que desestabilizaba el campo normativo, esta vez a cuenta de multiplicarlo y de banalizarlo. La etiqueta enarbolada por esta crítica es la de "constructivismo". La performatividad así entendida cifraba la agencia en el discurso. Ahora bien, la "lingüistificación" de la acción performativa presupone un sujeto ontológicamente trasparente y soberano, cuya agencia procede sin obstáculos del pensamiento y la voluntad. En realidad, es el menos- 
precio de la agencia del sujeto frente al Estado lo que conduce a esta idealización del dominio del lenguaje y del sujeto. Pero la aportación de la teoría de la performatividad no es, sin embargo, una recuperación nä̈ve de la agencia discursiva, sino más bien su limitación. Porque la limitación también abrirá posibilidades inéditas en nuestro acceso a los sujetos y sus cuerpos.

La primera restricción que experimenta la actuación performativa proviene del cuerpo. Las acciones corporales no son estrictamente lingüísticas debido fundamentalmente a su carácter mundano, es decir, porque acontecen ante los otros y ante su mirada, que escapa a nuestro control. El campo visual constituye un límite para la presencia de los cuerpos que va de la mano de los "marcos" de inteligibilidad, habilitadores al tiempo que selectivos y excluyentes. Esta limitación del marco concierne tanto a las propias herramientas del lenguaje y del pensamiento -las categorías-, como al carácter elusivo e inasequible del cuerpo y de la materia, irreductibles al mero discurso. De hecho, si hay géneros que se muestran insurgentes, ello obedece precisamente a su rebeldía frente a las normas, lo cual no sólo produce géneros fracasados, destinados a acabar en la vía muerta del no reconocimiento, pues, por su misma exposición material, dejan obstinadamente tras de sí fenómenos o efectos en el mundo. Butler ha enumerado y analizado múltiples formas de insurgencia que emplearon el cuerpo como principal instrumento. Entre ellas se encuentran la estilización corporal de las mujeres lesbianas "butch" o de los homosexuales afeminados, así como la ocupación sin permiso de la calle a nivel global. Pero también la hipérbole presente en las parodias de género de los drag, que también tiene lugar en el canto en español del himno norteamericano entonado por inmigrantes mexicanos. Y así podríamos sumar un largo etcétera.

De todo ello extraemos la enseñanza de que la política no puede hacerse sin los cuerpos. El pensamiento de Butler está atravesado por cierto materialismo, el que desde el principio ha alentado su trabajo en los estudios culturales, toda vez que el cuerpo habilita una particular ampliación de la política. El cuerpo es limitado, pero su misma vulnerabilidad alienta la posibilidad de pronunciar demandas compartidas y establecer alianzas políticas. La idea de una "performatividad plural" que Butler ha apuntado en sus últimos trabajos parte del hecho de que los cuerpos que se agrupan en la calle demandan ya con su sola presencia una existencia igualmente plural. Esta disposición a "espaciar el espacio de la aparición" -como se indica en el libro publicado con Athina Athanasiou, Dispossession - señala hacia una de las principales precondiciones de toda política o, si se quiere, es la expresión más acabada del derecho básico a tener derechos. Por de pronto, esa disposición es signo de que somos seres que cuentan con una integridad corporal y unas necesidades orgánicas inalienables. La necesidad corporal es una forma de desposesión y extrañamiento del sujeto, que 
se encuentra siempre requerido por y abierto a lo otro de sí, comenzando por sus propios sentidos. En la propia presencia de los cuerpos en las plazas públicas se pone en obra y se demanda en un solo lance dar satisfacción a las necesidades de los cuerpos y una distribución equitativa del espacio público, exigencias siempre en juego en toda política democrática. Pero la pluralidad reflejada por los cuerpos en la calle no siempre se compadece con la unidad de un proyecto político. Ahí se revela el carácter no elegido de nuestra existencia y la necesidad de pensar la cohabitación como otra de esas condiciones previas. Por último, en la actuación concertada de los cuerpos se constituye un "sujeto plural", que exhibe una naturaleza política radicalmente interdependiente. El cuerpo, que es la condición previa de todas estas formas de acción, es la condición de lo irrepresentable, necesariamente anterior a la política propiamente dicha y a los cauces de representación. El cuerpo se revela así como el límite constitutivo del campo político.

Los trabajos que forman parte de este número monográfico pretenden analizar y discutir los aspectos de la obra de Butler a que hemos aludido. En la sección de artículos, el trabajo de M.L. Femenías y R. Casale se ocupa del problema del método de este pensamiento, poniendo en valor su interés por la potencialidad emancipatoria de la contingencia. S. Reverter-Bañón propone distinguir en Butler dos teorías de las performatividad, una especial, que sería la desplegada por la primera obra de Butler, dedicada a dar cuenta de las posibilidades del género, y otra general, desarrollada en las últimas décadas, en la que se analizan las condiciones de una vida vivible. A. Jiménez Perona reconoce oportunamente la importancia en Butler de la "resistencia política" como actitud definitoria de la izquierda democrática, si bien encuentra algunos "cabos sueltos" en tal apuesta. Tal es el caso de la ausencia de "algún tipo de reconciliación" provechosa para la propia acción política, que Jiménez Perona encuentra en nuestra autora, pero también de su reducción de la noción de universalidad a fórmulas "no convencionales" o del hecho de que la mutua dependencia y la relacionalidad puedan llegar a entenderse como una nueva forma de "autenticidad", desde el momento en que no son aceptadas ni siquiera como un "universal existencial". L. Cadahia revisa la lectura que Butler realiza de la dialéctica del amo y el esclavo en Hegel, enriqueciéndola con las aportaciones de C. Malabou. Tal experimento arroja el saldo de una lectura alternativa y positiva de esa dialéctica como oportunidad para proceder a una elaboración ética del sí mismo, en lugar de considerarla en los términos de un trabajo ambiguo de sujeción y subjetivación, que no pueda desprenderse del aspecto negativo de las relaciones de poder, asfixiando los márgenes de la libertad y la autonomía. L. Posada propone la presencia en Butler de una idea de lo humano entendido como condición de exposición a otros y de consiguiente des- 
posesión, que la autora considera como posible punto de partida para una "política" libre de violencia. El trabajo de I. Gamero propone una lectura en clave epistemológica del trabajo de Butler, que la sitúa en una posición que califica de realismo moderado, pero al mismo tiempo también de universalismo, contraria tanto al escepticismo cartesiano como a las más recientes formas de constructivismo. Por último, A. Zaharijević y S. Milutinović Bojanić examinan de manera exhaustiva varias trayectorias del concepto de vida y de la condición de vida vivible o digna de ser vivida en la obra de Butler.

Entre las notas críticas y discusiones, que introducen un enfoque más polémico en el monográfico, P. Pérez analiza la acción de Rosa Parks desde las "teatralidades" de los activismos queer, y más concretamente de la llamada passing -"pasar por"-, conducta transgresora de barreras y prohibiciones. Por su parte, B. Sáez Tajafuerce y A. Armengol sugieren emprender una "lectura crítica" de la consulta soberanista realizada el 9N en Cataluña poniendo a Butler en diálogo con Foucault y Lacan. La propuesta de estos autores apunta a llevar lo Real y su "posibilidad radical" al campo político, leyendo la consulta del 9N no como una forma de resignificación o de rearticulación de lo simbólico, sino más bien como un "acto" en sentido lacaniano, que actualiza lo imposible, a saber, eso que no puede ser representado en absoluto y fuerza a ampliar el marco legal. El trabajo de E. Straehle interpreta la performatividad en Butler como profundización en la noción arendtiana de acción, un inicio de algo nuevo en el mundo que requiere de la presencia de otros, propiciando un diálogo siempre provechoso entre ambas pensadoras. I. Ortega y O. Belmonte proponen una lectura de la obra de Butler en clave fenomenológica a partir de los ensayos de Ahmed y Rodemeyer, así como de la obra escultórica y los textos de Louise Bourgeois. Por su parte, M. Cano se centra en el problema de la libertad en Butler y en la pregunta por la "agencia política", que se encontraría en un "doble filo" o en una "tensión", a saber, entre las condiciones que nos constituyen y someten, habilitándonos como sujetos, y la capacidad de producir normas a través del discurso. El trabajo de G. de Eugenio revisa las críticas de J. Massad a la representación del Otro como homosexual en el mundo musulmán, mostrando que la homosexualidad ha sido usada no sólo como un argumento al servicio de la guerra contra el árabe, sino también como un rasgo de deshumanización general. Por último, V. Dahbar propone pensar la acción política desde las nociones de marco y de precariedad, sosteniendo que con la subversión o insurrección ontológica tiene lugar el proceder que Butler denomina "enmarcar el marco", es decir, una operación que redibuja o vuelve a trazar el marco de inteligibilidad existente.

El monográfico contiene asimismo una entrevista con Judith Butler, en versión bilingüe inglés-castellano, realizada por Emma Ingala Gómez. Se trata de 
un valioso documento de diálogo directo con la autora en torno a cuya obra gira este monográfico, que ha permitido confirmar su singular capacidad para rehuir toda clasificación y encasillamiento y correspondiente militancia en la itinerancia de las reivindicaciones de agencia política y emancipación. Por último, la sección de reseñas se propone ofrecer una panorámica de las publicaciones recientes de Judith Butler, así como de estudios que se ocupan de su obra y cuestiones afines.

No queremos finalizar estas páginas de presentación del número sin dejar constancia de nuestro profundo agradecimiento a los autores que han contribuido al mismo, a los evaluadores que nos permitieron seleccionarlos, a los colegas y entidades que nos ayudaron a difundir la convocatoria de trabajos y a cuantos hacen posible esta Isegoría. 